\title{
Coral Bleaching Along Andaman Coast Due to Thermal Stress During Summer Months of 2016: A Geospatial Assessment
}

\author{
Prakash Chandra Mohanty ${ }^{1}$, Pitchiah Venkateshwaran ${ }^{2}$, Ranganalli Somashekharappa Mahendra ${ }^{1,}$, \\ Hyderabad Shiva Kumar', Tummula Srinivasa Kumar ${ }^{1}$, Nambali Valsalan Vinithkumar ${ }^{2}$, \\ Ramalingam Kirubagaran ${ }^{3}$, Sethuraman Ramesh $^{3}$, Raju Ramesh ${ }^{3}$, Dharmaraj Sathianarayanan ${ }^{3}$, \\ Vittal Doss Prakash ${ }^{3}$, Gidugu Ananda Ramadasss ${ }^{3}$, Sadananda Satish Chandra Shenoi ${ }^{1,3}$ \\ ${ }^{1}$ Indian National Centre for Ocean Information Services (INCOIS), Hyderabad, Telangana, India \\ ${ }^{2}$ National Institute of Ocean Technology (NIOT), Port Blair, Andaman \& Nicobar Islands, India \\ ${ }^{3}$ National Institute of Ocean Technology (NIOT), Chennai, Tamil Nadu, India
}

Email address:

mahendra@incois.gov.in (R. S. Mahendra)

${ }^{*}$ Corresponding author

To cite this article:

Prakash Chandra Mohanty, Venkateshwaran Pitchiah, Ranganalli Somashekharappa Mahendra, Hyderabad Shiva Kumar, Tummula Srinivasa Kumar, Nambali Valsalan Vinithkumar, Ramalingam Kirubagaran, Sethuraman Ramesh, Raju Ramesh, Dharmaraj Sathianarayanan, Vittal Doss Prakash, Gidugu Ananda Ramadass, Sadananda Satish Chandra Shenoi. Coral Bleaching Along Andaman Coast Due to Thermal Stress During Summer Months of 2016: A Geospatial Assessment. American Journal of Environmental Protection. Vol. 6, No. 1, 2017, pp. 1-6. doi: 10.11648/j.ajep.20170601.11

Received: December 5, 2016; Accepted: December 29, 2016; Published: January 28, 2017

\begin{abstract}
Coral bleaching reported in the North Bay, Andaman Islands during the April last week of 2016 due to thermal stress. The Coral Bleaching Alert System (CBAS) a service providing by Indian National Centre for Ocean Information Services (INCOIS) has reported the warning and the bleaching has been confirmed from the field survey conducted on April 26, 2016. As coral reef is important fragile eco-system of the shallow marine environment suffers due to human and natural impacts. Bleaching has been initiated as weather predictions of the various agencies have suggested the elevated temperatures in the Indian subcontinent this year. We have put forward our remote sensing analysis of coral bleaching warning as Alert Level-1 followed by the initiation of the coral bleaching in the in-situ observation at Andaman Islands enhances the credibility of satellite observation and the service of INCOIS. These results were useful for the coastal management authority for taking suitable measure and policy on important coral eco-system.
\end{abstract}

Keywords: Sea Surface Temperature, HotSpot, Degree of Heating Week, Eco-System, Time-Series, Remotely Operated Vehicle

\section{Introduction}

Corals are diverse shallow marine ecosystems that grow over geological time scales. They play an important role as a habitat for organisms in their environs, supporting a vast diversity of animal and plant species. For last few decades, the genetic heritage of coral ecosystems has been increasingly at risk. An increase of even $1-2^{\circ} \mathrm{C}$ above monthly mean can damage the symbiosis between coral and zooxanthalle, their algal symbiont $[1,2]$. The algae leave the shelter of the coral polyp and coral leaves their access to algal photosynthetic byproducts leads to the bleaching of corals. The Indian National Centre for Ocean Information Service (INCOIS) provides a series of products under a service called Coral Bleaching Alert System (CBAS). National Oceanic and Atmospheric Administration (NOAA) Advanced Very High Resolution Radiometer (AVHRR) satellite-derived night-time Sea Surface Temperature (SST) values are used to assess thermal stress in the coral environs ${ }^{2}$, which are in turn used to generate bleaching alerts. This 
method is similar to the NOAA Reef Watch program. This information highlights the early signs of increasing thermal intensity and the spatial extent of coral bleaching. Previous studies have discussed the impact of thermal stresses on coral reefs, their monitoring and assessment from a synoptic global view $[3,4,5,6,7]$. The corals of the Andaman Island were also victims of thermal stress due to elevated temperatures, which resulted in coral bleaching in the past during 1998, 2002, 2005 and 2010 [8, 9, 10, 11].

\section{Study Area}

The present study area Andaman Islands imparted with the richest coral diversity among all Indian reefs. Total of 177 species of hard corals falling under 57 genera have been reported from these islands [9]. The geographical constraints of the area are $6^{\circ} 45^{\prime}$ to $13^{\circ} 14^{\prime} \mathrm{N}$ Latitudes and $92^{\circ} 12^{\prime}$ to $93^{\circ}$ $57^{\prime}$ E longitudes consist of about 350 islands along with a number of expose islets and rocks, of which, only 38 are inhabited. Andaman \& Nicobar Islands divided into two districts as Andaman Islands and Nicobar Islands. Together they constitute a Union Territory (U. T.) of the union of India. The islands are away from the mainland and lack of the major river discharge into the sea result in the turbid free water. Hence this favorable condition enriched the coral environs. The Andaman Sea is one of the least explored regions of the Indian Ocean.

\section{Data and Methods}

The present study has been carried out using the remote sensing and simulated data, list is provided as Table 1.

Table 1. List of data used in current study.

\begin{tabular}{lll}
\hline Parameter & Source & Spatial Resolution (deg) \\
\hline LHF & ECMWF & 0.25 \\
SHF & ECMWF & 0.25 \\
Wind Components (U\& V) & ASCOT & 0.25 \\
PAR & MODISA & 0.042 \\
SST & NOAA, VHRR & 0.01 \\
\hline
\end{tabular}

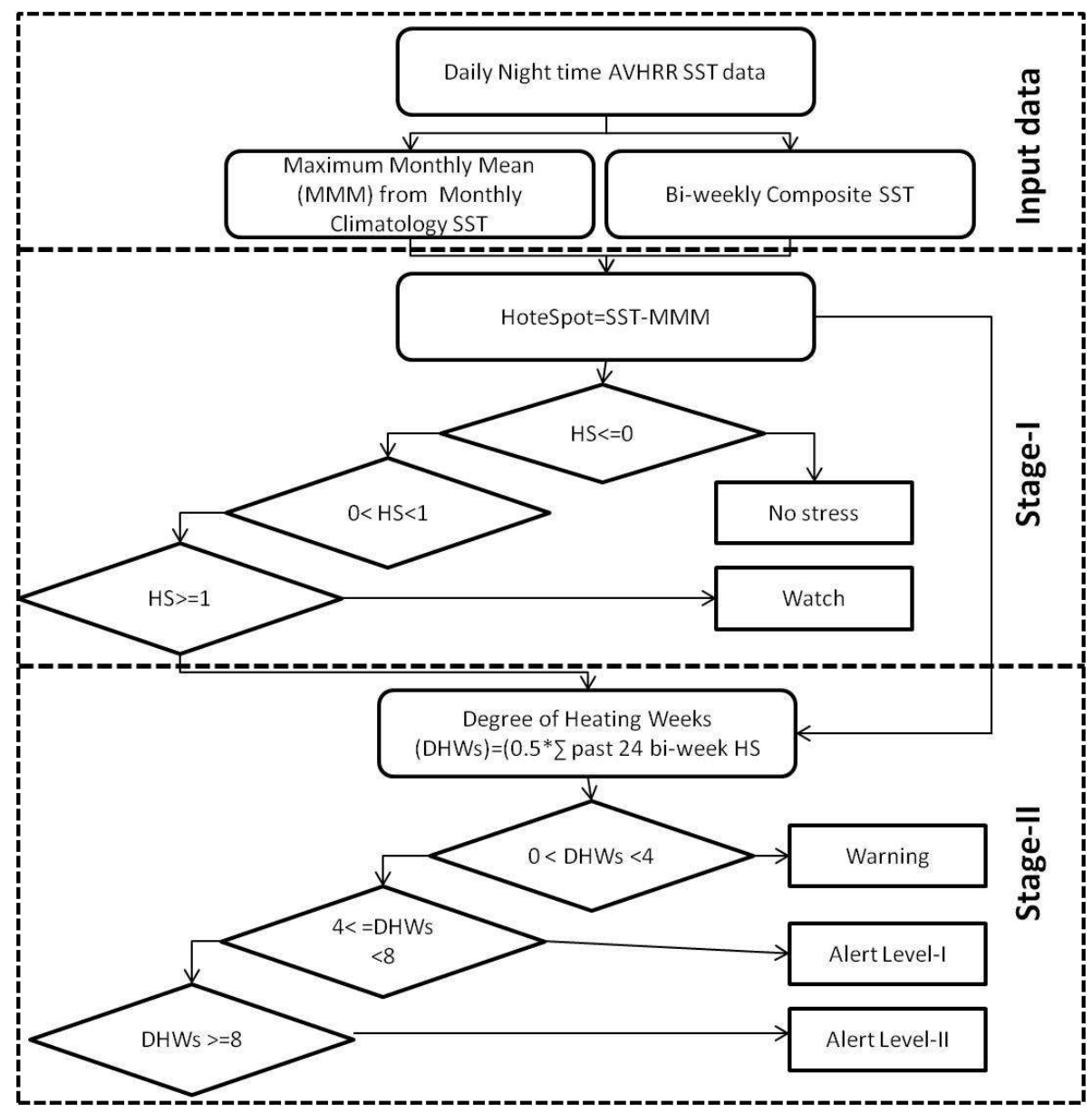

Figure 1. Flow chart depicting the assessment of thermal stress and bleaching warning.

The Multi-channel Sea Surface Temperature (MCSST) data from NOAA Advanced Very High Resolution Radiometer (AVHRR) was used for assess the thermal stress on coral reef around the Andaman reef environs during 28 March to 30th Apr2016. The calculation of thermal stress on coral reef $[8,18]$ using bi-weekly composite AVHRR SST data was carried out (Figure 1). In the present study the monthly climatology was extracted using daily long term time series AVHRR SST data from 1985 to 2016. In each pixel Maximum Monthly Mean (MMM) were extracted, 
which indicate that up to MMM level coral can be survive without thermal stress. In the primary analysis, the intensity of thermal stress was carried out using HotSpot (HS) analysis methods. The HotSpot is the degree of SST increase beyond the thermal tolerance level of the coral reef indicative of the thermal stress on the coral environs. HS value less than zero were categorized as "no Stress", the HS value within the range of 0 to $1^{\circ} \mathrm{C}$ is categorized as "watch" and values above $1^{\circ} \mathrm{C}$ was a threshold for thermal stress as warning leading to coral bleaching (Figure 2). Degree of Heating Weeks (DHWs) was calculated in order to find out the intensity and duration of thermal stress which lead to bleaching during study period. DHWs can be calculate the cumulative sum of 24 bi-weekly HS (only $>=1^{\circ} \mathrm{C}$ ) and categorized in to Warning, Alert Level-1 and Alert Level-2 (Figure 4). the value DHWs within the range of 0 to $4^{\circ} \mathrm{C}$ is said to be warning, the range of $4-8^{\circ} \mathrm{C}$ said to be significant bleaching (Alert Level-I )and above $8^{\circ} \mathrm{C}$ is consider as wide spread bleaching (Alert Level-II). Further, in-situ observations were carried out on Andaman coral reefs using an underwater Remotely Operated Vehicle (PROVe) mounted with a camera.

\section{Results}

The assessment of HotSpot and Degree of Heating Weeks (DHWs) generated using SST data revealed elevated temperatures during April-May 2016 in the surface waters of the Andaman and Nicobar Islands, Gulf of Mannar and Lakshadweep Islands. HotSpot is the temperature above the recorded monthly maximum of climatology recorded and DHW is the sums of HotSpots greater than $1^{\circ} \mathrm{C}$ recorded over the past three months (12-weeks). HotSpot recorded warning status from April 06, 2016 till the end of April 2016 (Figure 2). The DHW composites also have started depicting 'Warning' $\left(<4^{\circ} \mathrm{C}\right.$-week) to 'Alert Level-1' (4-8 ${ }^{\circ} \mathrm{C}$-week) from April 21 (Figure 3).

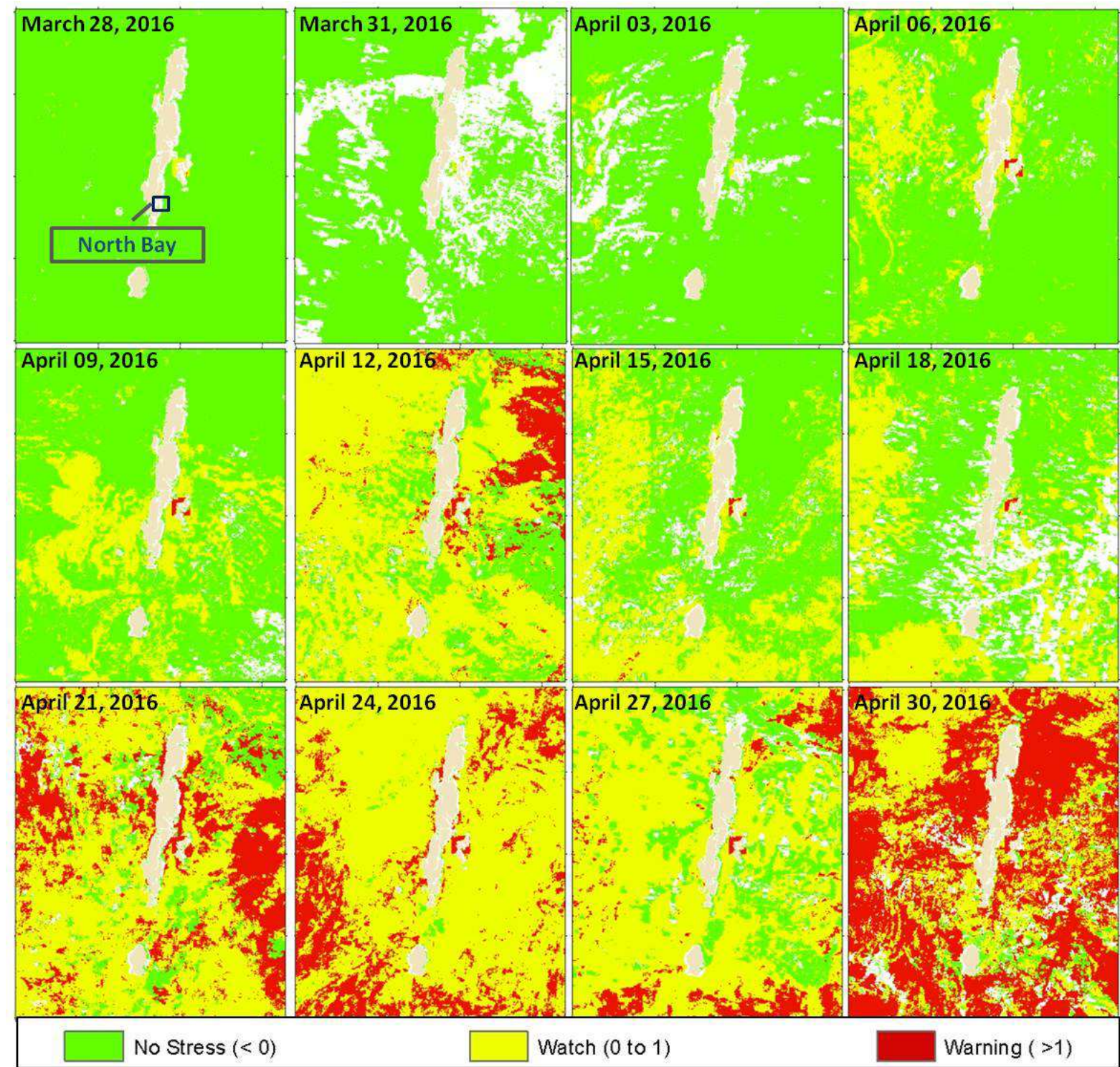

Figure 2. Time-series composites of bi-weekly HotSpot of the Andaman Islands recorded during 28 March to 30 April 2016. Location of in-situ observation carried out in the North Bay marked as box in top left composite. 

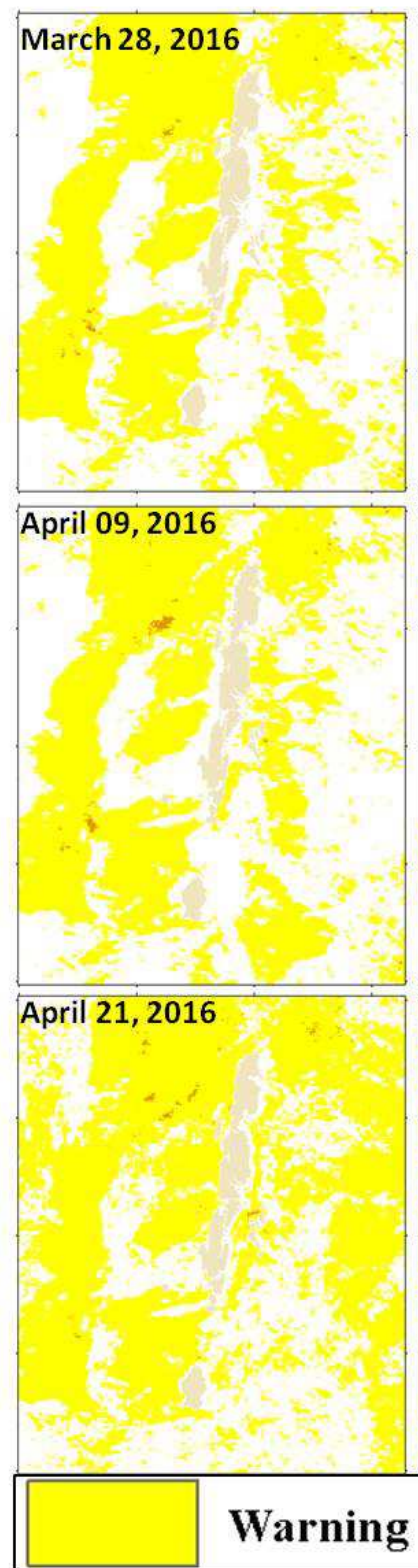
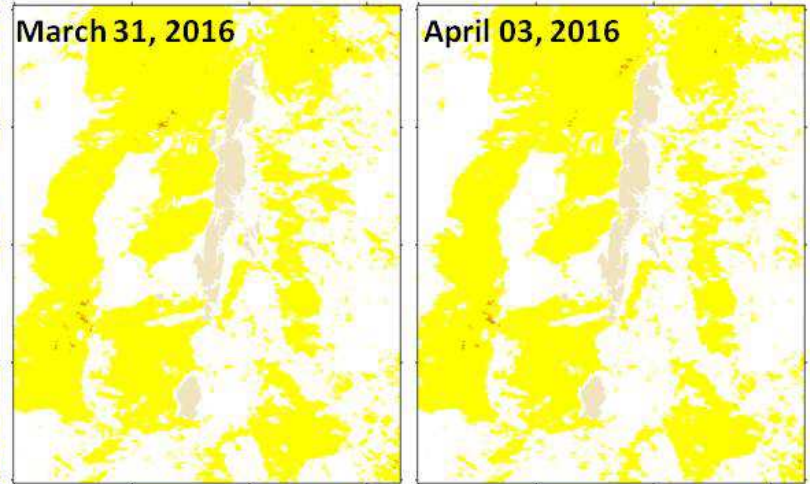

April 12, 2016
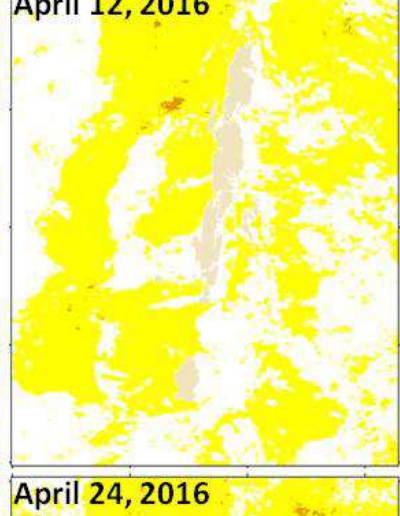

April 15, 2016
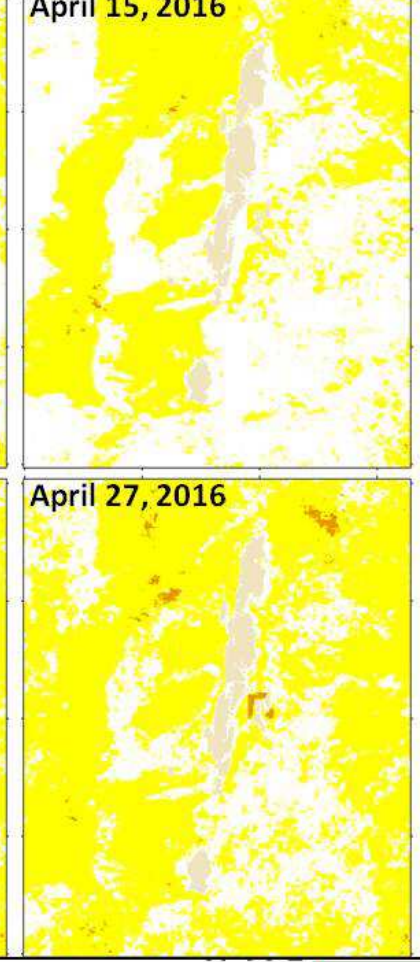

Alert Level-1

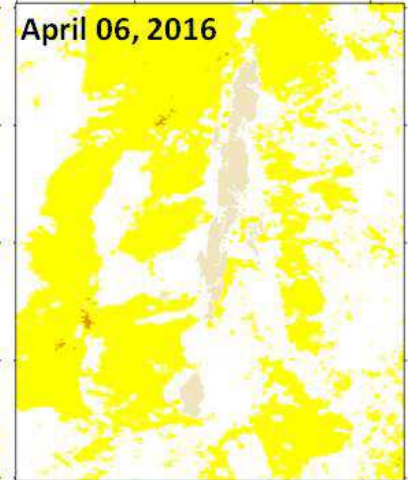

April 18, 2016

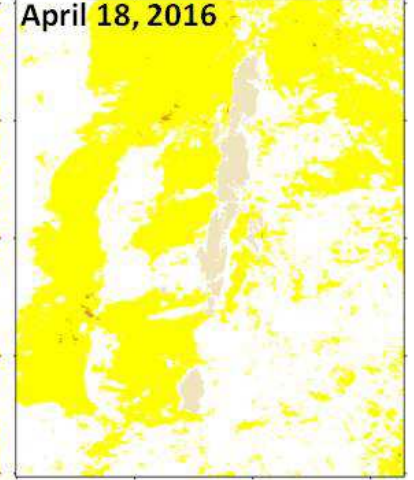

April 30, 2016

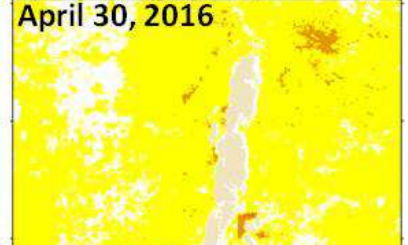

Figure 3. Plate showing the composites of DHWs during 28 March to 30 April 2016.

\subsection{Variations in Other Environmental Parameters}

HotSpot and DHW reveal intensified thermal stress, signaling bleaching in the Andaman coral environs during April 2016. To understand the cause of thermal stress, additional parameters like Latent Heat Flux (LHF), Sensible Heat Flux (SHF), Photosynthetic Active Radiation (PAR) and Wind Speed were compared with night time SST (Figure 4). SHF and PAR depict positive correlation with SST with correlation coefficients of 0.63 and 0.35 respectively. LHF and wind speed show negative correlations of -0.61 and -0.42 with SST respectively. Low wind speed caused lesser evaporation resulting in the accumulation of heat in the water column [12, 13]. The concurrent increase in PAR and SHF during this period also contributed to increased heating [1417]. In a nutshell, the interplay of all these varying environmental parameters confirms the developing thermal stress on corals lead to the bleaching in southern Andaman.

\subsection{In-Situ Observations}

To examine whether the corals have actually shown signs of bleaching, as revealed by the thermal stress assessed from satellite data, in-situ observations were carried out on Andaman coral reefs using an underwater Remotely Operated Vehicle (PROVe) mounted with a camera. This PROVe was developed by the National Institute of Ocean Technology (NIOT). Coral reef surveys were conducted at North Bay, Chidiyatapu, Jolly Buoy, Red skin and Grub Islands of South Andaman district. The surveys revel that the corals were healthy. Many branching corals started growing after the severe destruction of devastating tsunami of $26^{\text {th }}$ December 2004 and the beaching events of 2005 \& 2010. Coral reefs in most of the Andaman and Nicobar Islands are at resilient stage after these major events. The observations conducted at in the above mentioned areas and at North Bay 
on April 19, 2016 did not record any signs of bleaching (Figure 5 A\&B) in corals and associated organisms. However, subsequent observations at North Bay near Port Blair (location marked on Figure 2) recorded the onset of coral bleaching on April 26, 2016 (Figure 5 C\&D). The coral species Acropora, a species very sensitive to temperature changes shows signs of the onset of coral bleaching. Fungid species have also revealed signs of bleaching. During the observation the in-situ temperatures varied between 31.80 to $32.30^{\circ} \mathrm{C}$. Vertical profiles recorded the temperature of 32.30 , 32.00 and $31.50^{\circ} \mathrm{C}$ at the surface, $5 \mathrm{~m}$ and $10 \mathrm{~m}$ depth respectively.

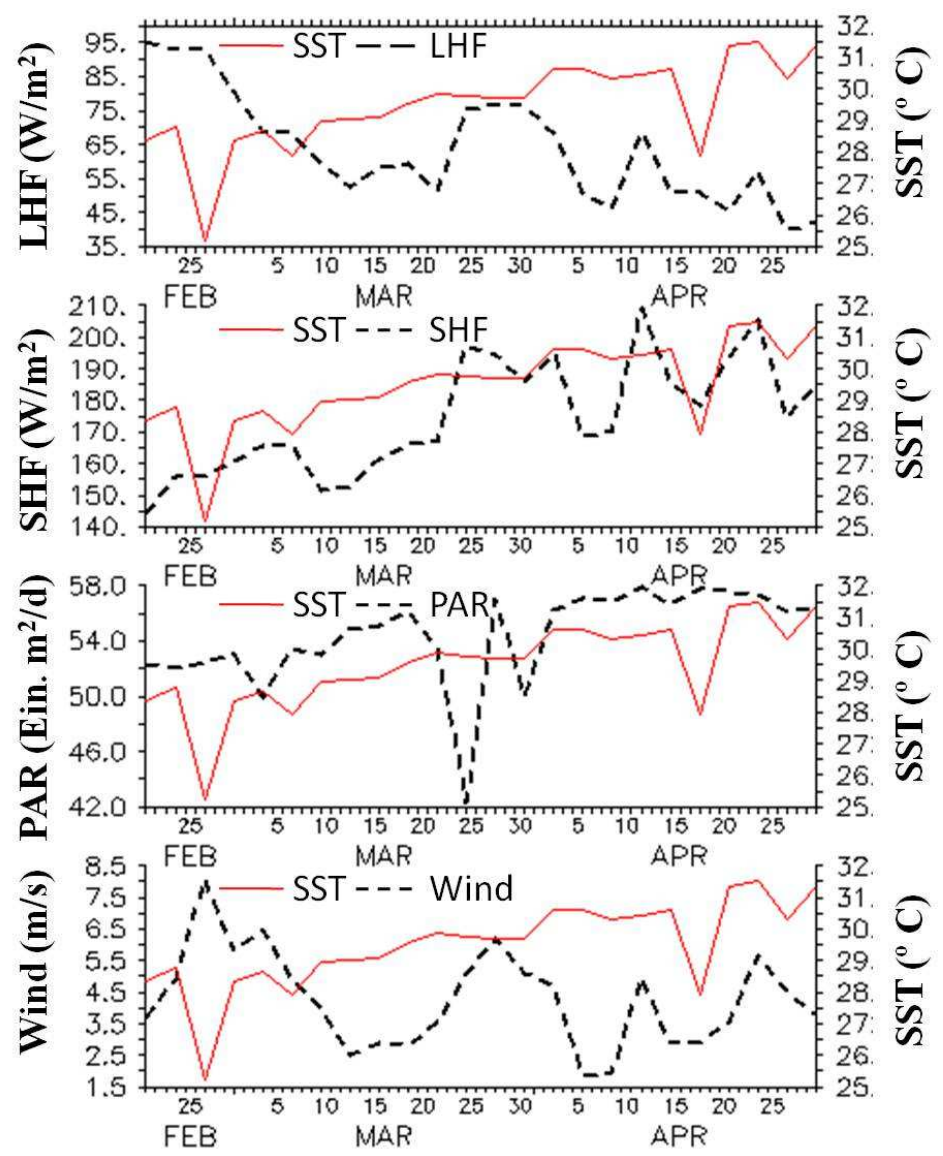

Figure 4. Bi-weekly time-series plots of the environmental parameters with SST.

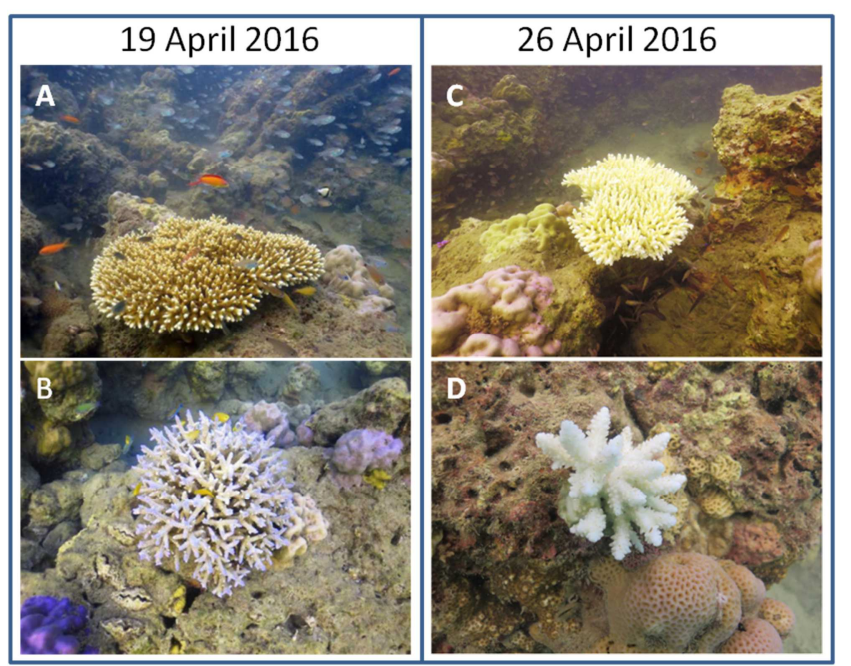

Figure 5. Underwater photographs of North Bay coral environs on 19 April $2016(A \& B)$ and 26 April 2016 (C\&D). The photographs made on 26 April show the primary signs of coral bleaching.

\section{Conclusions}

The in situ observations corroborate the bleaching alert products - HotSpot and DHWs - generated under CBAS program of INCOIS, as indicating their capacity in providing early signs of coral bleaching. The PROVe used for in-situ observations is very useful for such quick assessments of coral reef status. The outlook of thermal stress and probability of coral bleaching predicted by NOAA Reef watch is Alert Level-2 during May-August $2016^{[18]}$. If that is true, then bleaching of corals in the Andaman region might intensify further unless the temperature drops. Hence, it is important to monitor these changes continuously to understand the phenomenon and the extent of impact. These inputs are useful for further research and coastal management.

\section{Acknowledgements}

Authors are thankful to the NOAA AVHRR program for making their SST data available freely. Thanks to Dr. 
Vanessa Andrade, INCOIS for proof reading. This is INCOIS contribution number 272 .

\section{References}

[1] Berkelmans, R. and B. L. Willis, 1999. Seasonal and local spatial patterns in the upper thermal limits of corals on the inshore Central Great Barrier Reef, Coral Reefs, 18, 219-228.

[2] Reaser, J. K., R. Pomerance, and P. O. Thomas, 2000. Coral bleaching and global climate change: Scientific findings and policy recommendations, Conservation Biology, 14, 1500-1511.

[3] INCOIS, Coral Bleaching Alert System, http://www.incois.gov.in/portal/coralwarning. Accessed on May 02, 2016.

[4] Strong AE, Liu G, Meyer J, Hendee JC, Sasko D (2004) Coral Reef Watch 2002. Bul of Mar Sci, 75 (2), 259-268.

[5] Liu G, Strong AE, Skirving W (2003) Remote sensing of sea surface temperature during 2002 Barrier Reef coral bleaching. EOS, 84 (15), 137-144.

[6] Goreau TJ, Hayes R (1994) Coral Bleaching and Ocean "Hot Spots". Ambio, 23, 176-180.

[7] Montgomery RS and Strong AE (1995) Coral bleaching threatens ocean life, EOS, 75, 145- 147.

[8] Mohanty P. C., Mahendra R. S., Bisoyi H., Srinivasa Kumar T., Grinson George, Nayak S. and Sahu B. K. (2013). Assessment of the coral bleaching during 2005 to decipher the thermal stress in the coral environs of the Andaman Islands using Remote Sensing. European Journal of Remote Sensing, 46, 417-430.

[9] Krishnan P, Dam Roy S, Grinson George, Srivastava RC, Anand A, Murugesan S, Kaliyamoorthy M, Vikas N, Soundararajan R (2011) Elevated sea surface temperature during May 2010 induces mass bleaching of corals in the Andaman. Current Science, 100 (1), 111-117.
[10] Dharani G, Nazar AKA, Saravanane N et al (2012) On the recurrence of coral bleaching and recovery in North Bay, Port Blair, Andaman and Nicobar Islands. In: Venkataraman K, Raghunathan C, Sivaperuman C (eds) Ecology of faunal communities on the Andaman and Nicobar Islands. Springer, Berlin Heidelberg, 71-84.

[11] Marimuthu N, Dharani G, Vinithkumar NV et al (2011) Recovery status of sea anemones from bleaching event of 2010 in the Andaman waters. Curr Sci 101 (6), 734-736.

[12] Qu B., Gabric A. J., Zhu J., Lin D., Qian F., Zhao M., (2012). Correlation between sea surface temperature and wind speed in Greenland Sea and their relationships with NAO variability. Water Science and Engineering, 2012, 5 (3): 304-315 doi: 10.3882/j.issn.1674-2370.2012.03.006.

[13] Wang C., Robert H. Weisberg, and Yang H., (1999). Effects of the Wind Speed-Evaporation-SST Feedback on the El Nin oSouthern Oscillation. American Meteorological Society. Vol 56. P: 1391-1403.

[14] Ferrier-Pages C., Richard C., Forcioli D., Allemand D, 1 Pichon M, and Shick J. M. (2007). Effects of Temperature and UV Radiation Increases on the Photosynthetic Efficiency in Four Scleractinian Coral Species. Biol. Bull. 213: 76-87.

[15] Zhou Lian-Tong (2013). Influence of thermal state of warm pool in western Pacific on sensible heat flux. Atmos. Sci. Let. 14: 91-96. DOI: 10.1002/asl2.422

[16] Oda R., Kanda M., (2009). Cooling effect of Sea Surface Temperature of Tokyo Bay on urban air temperature. The seventh International Conference on Urban Climate, 29 June 3 July 2009, Yokohama, Japan.

[17] Buchheim, Jason. "Coral Reef Bleaching." Coral Reef Bleaching. http://www.marinebiology.org/coralbleaching.htm, Accessed on May 11, 2016.

[18] NOAA Reef Watch. http://coralreefwatch.noaa.gov/satellite/index.php, accessed on May 02, 2016. 